\title{
Iniciação Científica na Educação Básica: estudo de caso envolvendo uma escola privada de Porto Alegre
}

Jhonata Rodrigues de Brito ${ }^{1}$

Carlos Ventura Fonseca ${ }^{2}$

\begin{abstract}
Resumo:
A iniciação científica, apesar de geralmente identificada como atividade da Educação Superior, pode ser utilizada na Educação Básica para aprimorar ou despertar o espírito investigativo dos estudantes. Este trabalho apresenta um estudo de caso acerca da relevância da atividade de iniciação científica, no contexto de trabalho de uma escola privada, buscando relacionar a possível conexão dessa atividade com o desempenho escolar dos estudantes, partindo-se da percepção dos sujeitos envolvidos (docentes e discentes). Foram utilizados dois questionários como instrumentos de coleta de dados, sendo adotado o modelo de Educar pela Pesquisa da obra de Pedro Demo como referencial teórico principal do artigo. Os dados coletados referentes a questões abertas foram interpretados por meio da análise de conteúdo. Os resultados obtidos mostraram que houve convergência entre as visões discente e docente sobre os efeitos da iniciação científica, ressaltando-se que tal atividade trouxe melhorias no desenvolvimento de habilidades escolares (capacidade crítica, leitura, interpretação de textos, capacidade de concentração e aumento de interesse pelas aulas).
\end{abstract}

\section{Palavras-chave:}

Iniciação científica. Educação básica. Educação pela pesquisa.

\section{Scientific Initiation in Basic Education: a case study involving a private school in Porto Alegre}

\begin{abstract}
:
Scientific initiation, although generally identified as a Higher Education activity, can be used in Basic Education to improve or awaken the investigative spirit of students. This work presents a case study about the relevance of the scientific initiation activity in the work context of a private school seeking to relate the possible connection of this activity with the students' academic performance, starting
\end{abstract}

\footnotetext{
1 Licenciado em Ciências Biológicas pela Universidade Federal do Rio Grande do Sul (UFRGS). Professor de Biologia na rede privada de Porto Alegre. E-mail: jhonatarbrito@hotmail.com Orcid iD: http://orcid.org/0000-0002-4151-5890

2 Doutor em Educação, Mestre em Química (Linha de pesquisa: Educação em Química). Professor da Faculdade de Educação da Universidade Federal do Rio Grande do Sul (UFRGS), onde também atua no Programa de Pós-Graduação em Educação em Ciências: Química da Vida e Saúde. E-mail: carlos.fonseca@ufrgs.br Orcid iD: http://orcid.org/0000-0002-7464-0065
} 
from the perception of the subjects involved (teachers and students). Two questionnaires were used as data collection instruments and the Education by Research model of Pedro Demo's work was adopted as the main theoretical framework of the article. The data collected regarding open questions were interpreted through content analysis. The results obtained showed that there was convergence between the student and teacher views on the effects of scientific initiation, emphasizing that such activity brought improvements in the development of school skills (critical ability, reading, text interpretation, ability to concentrate and increased interest in classes).

\section{Keywords:}

Scientific initiation. Basic education. Education through research.

\section{Iniciación científica en Educación Básica: un estudio de caso de una escuela privada en Porto Alegre}

\section{Resumen:}

La iniciación científica, aunque generalmente se identifica como una actividad de la Educación Superior, se puede utilizar en la Educación Básica para mejorar o despertar el espíritu investigador de los estudiantes. Este trabajo presenta un caso de estudio sobre la relevancia de la actividad de iniciación científica, en el contexto laboral de una escuela privada, buscando relacionar la posible conexión de esta actividad con el desempeño académico de los estudiantes, a partir de la percepción de los sujetos involucrados (docentes y estudiantes). Se utilizaron dos cuestionarios como instrumentos de recogida de datos, adoptando el modelo de educar a través de la investigación basada en el trabajo de Pedro Demo como marco teórico principal del artículo. Los datos recopilados sobre preguntas abiertas se interpretaron mediante análisis de contenido. Los resultados obtenidos mostraron que hubo convergencia entre las visiones del alumno y el docente sobre los efectos de la iniciación científica, destacando que dicha actividad trajo mejoras en el desarrollo de las habilidades escolares (capacidad crítica, lectura, interpretación de textos, capacidad de concentración y aumento de interés por las clases).

\section{Palabras clave:}

Iniciación científica. Educación básica. Educación a través de la investigación.

\section{Introdução}

Pode-se considerar que as origens da iniciação científica (IC) brasileira têm raízes no ano de 1951, com a criação do Conselho Nacional de Desenvolvimento Científico e Tecnológico (CNPq). Entretanto, a atividade de financiamento regular via editais, com amplo alcance e capilaridade de IC, em instituições educacionais, é uma prática relativamente recente na história do país, considerando-se que foi somente no início dos anos 1990, que o CNPq viabilizou as primeiras edições do Programa Institucional de Bolsas de Iniciação Científica (PIBIC). Este foi pensado como um instrumento nacional de fomento/incentivo para a atividade científica para estudantes da educação superior (DAMINELLI, 2018).

Apesar de sua origem estar localizada no ensino superior, a atividade de IC também pode ser pensada/realizada no campo de trabalho da educação básica (XAVIER; ALMEIDA, 2019). Em meados dos anos 1980, essa ideia foi pioneiramente posta em prática a partir do Programa de Vocação Científica (PROVOC) da Escola Politécnica de Saúde Joaquim Venâncio, da Fiocruz, sendo que este proporcionava a inserção de estudantes do ensino médio em atividades de IC, havendo planejamento e acompanhamento adequados (DAMINELLI, 2018; SOUSA et al., 2007; 
XAVIER; ALMEIDA, 2019). No cenário brasileiro das duas primeiras décadas do século XXI, outros programas foram sendo criados, oportunizando o desenvolvimento de atividades de IC na educação básica, como, por exemplo: o Programa Institucional de Bolsas de Iniciação Científica Júnior (PIBIC-Júnior), o Programa Institucional de Bolsas de Iniciação Científica para o ensino médio (PIBIC-EM) e o Programa da Olimpíada Brasileira de Matemática das Escolas Públicas (OBMEP) (DAMINELLI, 2018).

Ainda que haja essas alternativas, constata-se que existem, proporcionalmente ao tamanho do território brasileiro e da diversidade de ambientes educacionais, poucos estudos publicados que abordam a IC no âmbito da escola básica (LIMA; CARVALHO, 2017; BRITO; FONSECA, 2020). As pesquisas produzidas, de um modo geral, revelam ganhos para os aprendizes de IC, havendo evidências de progressos dos sujeitos em diferentes habilidades aprendidas na escola (DAMINELLI, 2018; DAPPER; LEITE, 2016; PRESTES; SILVA, 2009; SOUZA et al., 2019; XAVIER; ALMEIDA, 2019).

Partindo-se dessa perspectiva, este trabalho apresenta-se como um estudo qualitativo/estudo de caso (LÜDKE; ANDRÉ, 1986) acerca da relevância da atividade de iniciação científica (IC), no contexto de trabalho da educação básica de uma escola privada, buscando relacionar a possível conexão dessa atividade com o desempenho escolar dos estudantes, partindo-se da percepção dos sujeitos envolvidos (docentes e discentes). A investigação foi conduzida com estudantes e docentes do Grupo de Iniciação Científica (GIC) da escola privada citada, localizada no município de Porto Alegre - Rio Grande do Sul, durante o ano de 2020. Destaca-se que a realização da pesquisa acadêmica em tela compôs o trabalho de conclusão de curso de graduação (curso de Licenciatura em Ciências Biológicas) do primeiro autor deste artigo (que foi defendido no segundo semestre do ano de 2020).

\section{Conexões entre o tema da IC na educação básica e a literatura acadêmica}

Mazon e Trevizan (2001, p. 86) defendem que a atividade de IC é um instrumento formativo que proporciona "o treinamento em metodologia científica, o desenvolvimento da análise e do julgamento crítico, e o incentivo à criatividade e à inovação". Também pode ser compreendida como um conjunto de práticas educacionais típicas do "ensino superior e médio cada dia mais presente, em virtude de sua importância, seus resultados e o envolvimento crescente, sobretudo de alunos universitários de diferentes áreas do conhecimento" (SAKAMOTO; SILVEIRA, 2019, p. 5). Não se pode esquecer a vinculação essencial da atividade de IC com os respectivos projetos de pesquisa, oportuna e necessariamente orientados por docentes que possuem bagagem acadêmica suficiente para a condução das atividades relacionadas (MASSI; QUEIROZ, 2010).

Ainda que a IC seja relatada na literatura educacional como uma atividade mais vinculada à educação superior (DAMINELLI, 2018; MASSI; QUEIROZ, 2010; MAZON; TREVIZAN, 2001; SAKAMOTO; SILVEIRA, 2019), pesquisas que abordam a educação básica também podem ser encontradas. No contexto da educação básica, a IC pode assumir o potencial de despertar/desenvolver os aportes iniciais para a formação de uma postura investigativa e criativa dos sujeitos, através de atividades que permitam "aprimorar os conhecimentos e as habilidades para acessar, selecionar, processar, analisar e utilizar dados, objetivando-se o aprofundamento dos conceitos" e sua relação com a "qualidade de vida da comunidade" (GONZAGA; OLIVEIRA, 2019, p. 112). Alguns exemplos de produções acadêmicas que discorrem sobre o tema da IC na escola básica, e sobre os possíveis ganhos qualitativos e características específicas de tal relação, serão discutidos a seguir.

O trabalho de Silva (2018) evidenciou as atividades de um projeto de IC para os estudantes do ensino médio, que buscou aproximar o cotidiano dos estudantes da ciência (tratando temas de Biologia). Em decorrência do projeto referido, conforme relata a autora citada, foi constatado que os estudantes apresentaram: melhora no rendimento escolar geral; aprendizado em exercitar o pensamento crítico; maior interesse pelo conteúdo (SILVA, 2018). 
Rocha e Simião-Ferreira (2020) descreveram um projeto de IC em uma escola pública, destacando a possibilidade de ensino por meio da investigação científica, como forma de atração do interesse dos sujeitos. Gauna et al. (2018) relataram o trabalho realizado em uma escola pública, na qual, durante as atividades de IC com estudantes do ensino médio, buscaram aproximações dos discentes com a cultura científica. O trabalho citado destacou, ainda, o potencial desse tipo de atividade para que o enfoque interdisciplinar do conhecimento seja percebido pelos sujeitos, bem como as oportunidades de compartilhamento do que foi aprendido/construído e o desenvolvimento da autonomia de cada estudante.

Castro et al. (2018) glosaram a pertinência da pesquisa na escola, tendo-se em vista a possibilidade dos estudantes participarem com questões de interesse pessoal, aprofundando conhecimentos e construindo opiniões consistentes sobre diferentes achados oriundos dos projetos com os quais se envolvem. Araújo (2018), por sua vez, evidenciou a possibilidade de a atividade de IC, no ensino médio, promover a centralidade/protagonismo dos discentes no ambiente de ensino e aprendizagem, além de proporcionar formação para a cidadania, ao viabilizar a investigação de temas de alcance local e global. Longhi e Schroeder (2012), por outro lado, salientaram a dificuldade de realização da atividade de IC na escola básica, considerando-se as formas diversas de sua efetivação, no ambiente escolar, e a organização interna de cada instituição.

Dapper e Leite (2016) salientaram que a IC, no ensino médio, pode promover aproximações profícuas da escola com a universidade, além de ocasionar melhora do rendimento escolar (criticidade, escrita e interpretação de textos). Com abordagem similar, Peres e Cajueiro (2018) mostraram que, a partir da IC na escola, as atividades relacionadas normalmente requerem autonomia discente, estimulando-a, tornando cada sujeito mais confiante para construir novos conhecimentos.

A partir dessas produções acadêmicas, depreende-se que a IC na educação básica é compreendida como atividade com excelente potencial pedagógico, já que tende a promover situações de aprendizado eficientes e que se diferenciam do modo de funcionamento tradicional das escolas, normalmente centrado na aula expositiva (DEMO, 1992). As atividades correlacionadas tendem a aproximar a educação e a pesquisa, sendo esse exatamente o tema da próxima seção deste artigo.

\section{Educar pela pesquisa: em busca de um referencial teórico}

A busca por um referencial teórico educacional que estabeleça conexões entre os processos educacionais e a pesquisa encontra em Pedro Demo uma alternativa muito bem estruturada (DEMO, 1992, 2015). O autor defende a pesquisa como princípio científico/educativo (DEMO, 1992), recorrendo à necessária dualidade que a caracteriza - qualidade formal/política - que deveria orientar o trabalho na educação básica. Com qualidade formal, o autor mencionado considera ambientes pedagógicos que: desmistifiquem o conceito de pesquisa, de modo que esta deixe de ser entendida como atividade restrita a círculos acadêmicos sofisticados, passando a ser posta em prática nas escolas, para sujeitos das mais variadas idades; estejam imersos na realidade, possibilitando a criação de soluções e o processo de aprender a aprender; estimulem a elaboração própria, com base na pesquisa; que promovam a discussão entre os sujeitos e disponibilizem diferentes materiais escritos de referência; enfatizem a aplicação do conhecimento produzido (aproximação com o cotidiano); explorem materiais didáticos que não se reduzam a meros manuais informativos, mas que requeiram uma posição de questionamento da realidade e dos problemas que desta emanam.

Ainda, segundo o autor citado, a qualidade política estaria relacionada à visão de pesquisa como elemento partícipe do processo emancipatório da sociedade (formação dos sujeitos com base na orientação epistemológica histórica, crítica, autocrítica, com capacidade/consciência para conhecer, lidar com a informação e com diferentes problemas cotidianos). As escolas que se apropriassem dessa perspectiva, assumiriam alguns compromissos, como: construção curricular 
que privilegiasse interpretação da realidade como elemento balizador das áreas do conhecimento e do trabalho docente; exercício de movimentos de cidadania (como eleição de representantes de turmas, espaços para debate e divulgação de informação da escola, construção coletiva de regras para uso dos espaços, divulgação de direitos fundamentais de diferentes grupos que compõem a sociedade etc.); organização de eventos que promovam conhecimentos curriculares em conexão com temas e problemas relacionados a questões políticas, econômicas, culturais e de organização democrática do país, incluindo-se a relação da escola com a comunidade escolar, com organizações locais/regionais e seus atores (DEMO, 1992).

Nesse sentido, os estudantes de educação básica, no modelo de "Educar pela Pesquisa" proposto pelo autor (DEMO, 2015), caracterizam-se por: serem sujeitos ativos e mobilizados pelos processos que ocorrem na sala de aula, compondo, com o professor, a equipe de trabalho que se constitui no ambiente de aprendizagem e ensino; atuarem de modo grupal, sem esquecerem a responsabilidade individual (e as iniciativas pessoais), construindo condições de convivência e de solidariedade; não se fundamentarem pela mera reprodução; procurarem materiais que propiciem a realização de diferentes etapas da pesquisa, exercitando a leitura; buscarem interpretar, compreender o que já existe sobre determinado tema/problema; partirem de questionamentos reconstrutivos, ou seja, problemas que possibilitem a elaboração de proposta própria (formulando redação e experiência próprias, com argumentação bem fundamentada). Segundo o autor citado, o professor, por seu turno, deve: trabalhar pela reconstrução do projeto pedagógico próprio/práticas imbricadas neste; constituir-se como autor de textos científicos e materiais didáticos com base no questionamento constante; inovar a prática/propostas didáticas próprias, trabalhando pelo máximo rendimento do estudante (exercitar a autoria, sem desconhecer os demais autores); construir e executar hipóteses de trabalho, coletar dados, relacionar teoria e prática na busca de propostas alternativas para a sala de aula (próprio trabalho como professor); divulgar o próprio trabalho, comunicando-o através de diferentes meios.

Ressalta-se, pelo que foi exposto, que os papéis de professor e estudantes assumem uma dimensão bastante diferente da conhecida na sala de aula tradicional, na concepção teórica do "Educar pela Pesquisa", que se mostra convergente com a ideia de se realizar a IC na educação básica (tema central deste artigo). Na próxima seção, serão descritos os movimentos de pesquisa que embasaram a investigação educacional ora apresentada.

\section{Metodologia}

A pesquisa ora apresentada tem cunho qualitativo, caracterizando-se como um estudo de caso (LÜDKE; ANDRÉ, 1986) sobre atividades de IC ocorridas na escola privada citada na introdução deste artigo (que compreende turmas de educação infantil, ensino fundamental e ensino médio, atendendo um número aproximado de 800 estudantes). Esse tipo de estudo educacional, além de apresentar dados descritivos, busca delimitar e interpretar as informações de certo contexto, buscando diferentes pontos de vista que possam surgir da situação investigada (LÜDKE; ANDRÉ, 1986). A pesquisa interpelou sujeitos da escola privada citada, quais sejam: estudantes (do ensino fundamental e do ensino médio), bem como professores que atuavam no ensino fundamental e no ensino médio, todos ligados ao GIC da escola (os participantes desse grupo desenvolviam atividades de IC na referida instituição). A aproximação com o GIC ocorreu pelo contato prévio do primeiro autor deste artigo com a instituição, que realizava estágio profissional na escola em tela.

Para realização da pesquisa, foram solicitadas, previamente, autorização da instituição escolar de educação básica e do Comitê de Ética em Pesquisa da universidade à qual os autores deste artigo estão afiliados. Assim, foi realizado o contato com os pais/responsáveis pelos estudantes, enviando-se o Termo de Consentimento Livre e Esclarecido (TCLE), com autorização do envio posterior aos 
estudantes menores de 18 anos de idade, do Termo de Assentimento Livre e Esclarecido. Para os docentes da escola, foi enviado apenas o TCLE. Os sujeitos interpelados também receberam o respectivo instrumento de coleta de dados da pesquisa: um questionário para os estudantes, denominado questionário $\mathrm{E}$, com 10 questões; e um questionário para os docentes, denominado questionário $\mathrm{D}$, com 13 questões. Neste artigo, serão apresentadas e discutidas as respostas a questões selecionadas, consideradas mais pertinentes e relevantes, diante do conjunto de dados que foi obtido.

Após a delimitação das questões básicas de estudo e do referencial teórico principal da pesquisa, conforme sugerem Lüdke e André (1986), os dados foram coletados, durante os meses de maio e junho do ano de 2020, por meio da plataforma Google Forms. Os questionários apresentavam perguntas dissertativas (abertas) e objetivas (fechadas), que investigavam eventuais efeitos dos projetos e práticas de IC no desempenho escolar dos estudantes, a partir da percepção dos sujeitos envolvidos.

Por fim, em uma fase analítica do estudo de caso (LÜDKE; ANDRÉ, 1986), as respostas foram interpretadas, qualitativamente, tendo como base a literatura previamente consultada e apresentada em seções anteriores deste artigo. Foram feitas quantificações relacionadas às respostas relacionadas às questões objetivas, enquanto que os dados obtidos em perguntas abertas foram analisados com base na análise de conteúdo (BARDIN, 2010). Assim, foi adotado "um conjunto de técnicas de análise das comunicações que utiliza procedimentos sistemáticos e objetivos de descrição do conteúdo das mensagens", o que possibilitou "a inferência de conhecimentos relativos às condições de produção" dos dados obtidos (BARDIN, 2010, p. 40).

\section{Resultados e discussões}

A amostra de sujeitos interpelados foi composta por: 08 estudantes do sexo masculino e 03 do sexo feminino (faixa etária dos 13 aos 19 anos), sendo que a distribuição por etapas está apresentada no Gráfico 1. A amostra de professores apresentava 04 sujeitos (sendo 03 do sexo feminino e 01 do sexo masculino, sendo a faixa etária dos 42 aos 55 anos); 03 sujeitos atuavam na área de Ciências da Natureza (Biologia, Física e Química) e apenas 01 sujeito atuava na área de Linguagens (Língua Portuguesa, Língua Estrangeira).

Gráfico 1 - Participação dos estudantes segundo etapas da educação básica

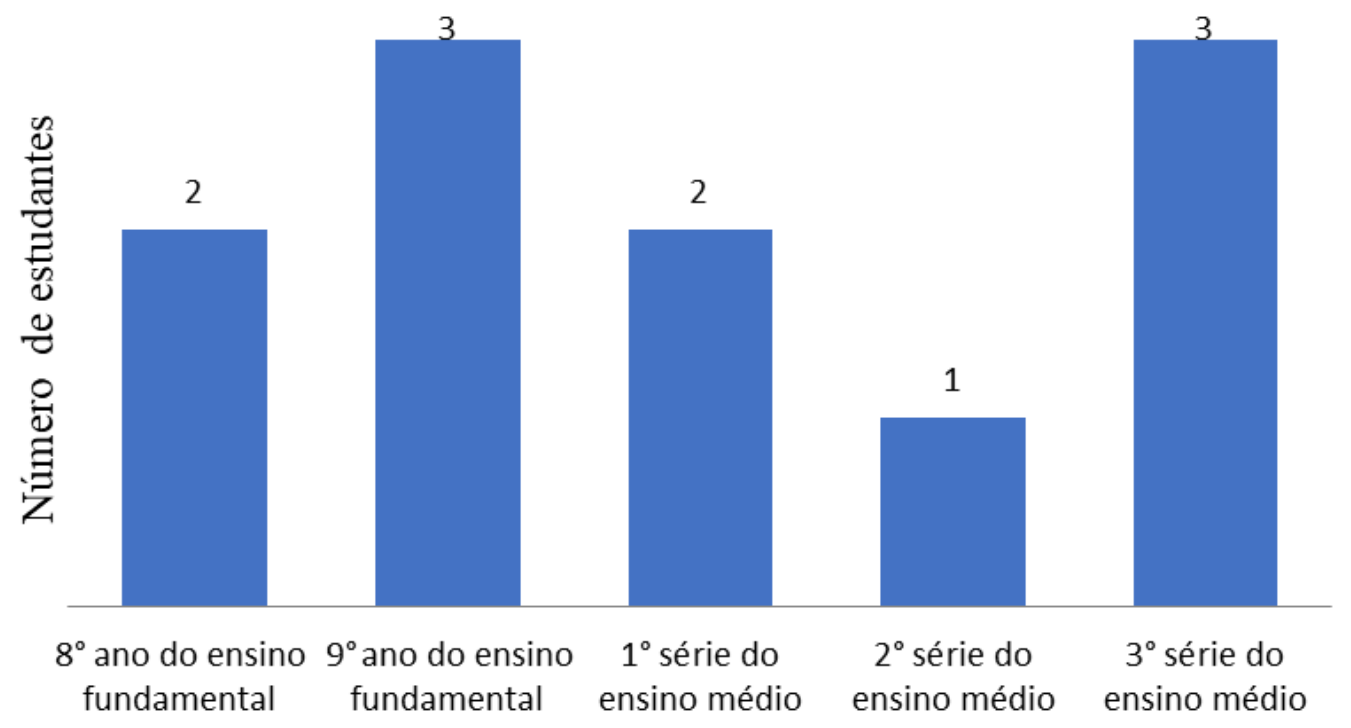

Fonte: Elaborado pelos autores com base nos dados obtidos. 
As respostas ao questionário $\mathrm{D}$ mostraram que todos os professores se envolveram com pesquisa antes de ingressarem no GIC e que todos possuem mestrado na área da Educação. Um dos professores tem doutorado e o outro possui 03 especializações (em áreas não especificadas). Neste artigo, os(as) professores(as) serão nomeados(as) por siglas (P1, P2, P3, P4), a fim de que seja mantido o anonimato destes(as).

Não foram identificadas razões para a ocorrência de um número relativamente diminuto de estudantes como integrantes do GIC, considerando-se o universo global dos matriculados na escola. Possivelmente, essa situação estivesse relacionada ao fato de como se dava a participação nas atividades de IC do grupo citado: uma atividade que era disponibilizada aos discentes (pela escola), mas que não se apresentava como pré-requisito para aprovação (não era obrigatória).

Nesse sentido, configurava-se como uma atividade extracurricular como qualquer outra (futebol, por exemplo), sendo realizada conforme o interesse discente (o envolvimento era espontâneo). Aqui, pondera-se sobre o efeito limitante dessa estrutura de trabalho, que poderia, de uma forma mais contundente, considerar as atividades de IC como um efetivo espaço/tempo curricular, conferindo à pesquisa um status mais elevado no ambiente escolar, conforme sugere Demo (1992, 2015).

\section{Investigando as respostas dos(as) estudantes}

A partir da primeira pergunta do questionário $\mathrm{E}$ (que indagava sobre o tempo de participação de cada estudante no GIC), evidenciou-se que grande parcela dos estudantes havia ingressado no triênio de 2017-2019 (Gráfico 2). Salienta-se, entretanto, que houve evasões de estudantes ao longo do período, cujo número absoluto não foi disponibilizado pela escola.

\section{Gráfico 2 - Número de novos estudantes no GIC (ingressantes por ano)}

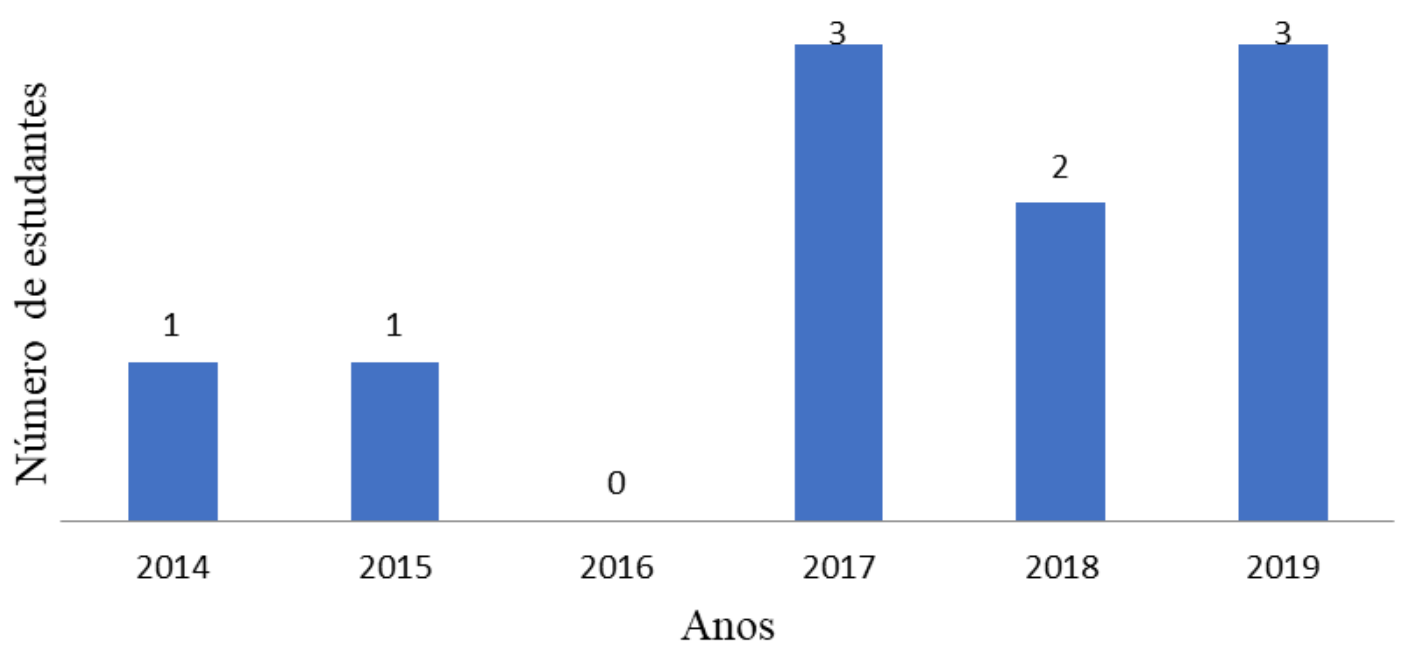

Fonte: Elaborado pelos autores com base nos dados obtidos.

A pergunta 02 do questionário $\mathrm{E}$ - aberta - indagava sobre os meios pelos quais cada estudante conheceu o GIC. Foram obtidas quatro categorias de respostas, após análise de conteúdo destas, quais sejam: categoria 1 - por meio do professor responsável (8 estudantes), categoria 2 - por meio da escola (1 estudante), categoria 3 - por meio dos colegas (1 estudante) e categoria 4 por iniciativa própria (1 estudante). Aqui, destaca-se a importância do professor responsável pela organização das atividades do GIC, agindo como incentivador e divulgador das atividades de IC para os estudantes, bem como um orientador geral dos sujeitos. Conforme assinalam Daminelli 
(2018) e Massi e Queiroz (2010), a relação estabelecida entre estudantes e o professor/orientador é um aspecto relevante para a atividade de IC, que pode proporcionar troca de informações e experiências pessoais entre estes.

A terceira pergunta do questionário E indagava sobre o título do projeto de pesquisa que cada estudante estava desenvolvendo ou havia desenvolvido no GIC. A análise de conteúdo das respostas possibilitou a categorização dos trabalhos, sendo adotadas/adaptadas de categorias previamente conhecidas de um evento qualificado de IC (UFRGS, 2020), obtendo-se o Quadro 1. A escolha pela utilização de categorias a priori, para essa análise específica, ocorreu pela pertinência com que as áreas de conhecimento foram convenientemente categorizadas no evento em tela. Destaca-se que o número total de trabalhos é maior que o número global de estudantes, considerando-se que alguns destes realizavam mais de um trabalho de pesquisa (IC) e/ou houve trabalhos em grupos.

Quadro 1 - Categorização dos objetos de pesquisa dos projetos do GIC

\begin{tabular}{|l|l|}
\hline Categoria Temática & Objetos investigados nos projetos de IC (ocorrência) \\
\hline Ciências Biológicas & Carvão ativado (1); Folhas (1); Arroio Dilúvio (1); \\
\hline Ciências Exatas & $\begin{array}{l}\text { Estatística e futebol (3); Acrilamida (1); Fluídos (1); Som (1); Magne- } \\
\text { tismo (1); Aceleração Gravitacional (1); Velocidade e tempo (1); }\end{array}$ \\
\hline Ciências da Terra & Rochas (2); Solo (1); \\
\hline Ciências Humanas & Transporte público (1). \\
\hline
\end{tabular}

Fonte: Elaborado pelos autores com base nos dados obtidos.

Verificou-se a predominância de trabalhos da categoria Ciências Exatas ( $\mathrm{N}=9$ trabalhos), seguida pela categoria Ciências da Terra $(\mathrm{N}=3$ trabalhos) e pela categoria Ciências Biológicas $(\mathrm{N}=$ 3 trabalhos). A categoria Ciências Humanas foi a menos frequente ( $\mathrm{N}=1$ trabalho). Aqui, aponta-se uma limitação da investigação ora descrita: não foram identificadas as causas desse resultado (pequena penetração da área de Ciências Humanas, especificamente, como campo de trabalho dos projetos de IC dos sujeitos), de modo que o estudo deixou uma dúvida em relação a esse resultado: há um baixo grau de envolvimento de docentes/orientadores da área de Ciências Humanas com a atividade de IC na escola citada por vontade destes, ou os professores não se envolvem com a atividade de IC, pois não há demanda discente em realizar trabalhos relacionados ao campo de conhecimento mencionado? Docentes dessa área, na escola referida, seriam menos identificados com a IC ou com a pesquisa na educação básica, isso teria relação com sua (falta de) formação em nível de pós-graduação?

O instrumento de coleta de dados (questionário E) utilizado não foi suficiente para fornecer elementos que respondessem a tais perguntas, o que denota a necessidade de que pesquisas futuras com esse enfoque, IC em escolas, atentem para essa possível particularidade. Segundo Demo (1992, 2015), seria importante que houvesse o envolvimento dos docentes com as atividades de pesquisa (englobando-se todas as áreas curriculares das escolas), de modo que cada escola propiciasse, na sala de aula e em espaços/tempos diversos, oportunidades de processos formativos mais amplos, fazendo com que a qualidade formal/política das atividades de ensino e aprendizagem desenvolvidas, no ambiente educacional, fosse potencializada.

Respostas à questão 04 (do questionário E) informaram que 11 projetos de IC foram realizados individualmente e 05 foram realizados com a participação de colegas, enquanto que respostas à questão 05 (do questionário E) revelaram que 04 estudantes já tinham participado de outros trabalhos de IC em anos anteriores no GIC. Segundo Demo (2015), a construção (na escola) de atividades de pesquisa em grupo e, concomitantemente, havendo desenvolvimento de iniciativas individuais, seria relevante para a constituição de processos de socialização, de convivência com regras, de trabalho coletivo para obtenção de objetivos que sejam comuns ao grupo e de negociação 
de consensos entre os sujeitos, projetando-se, de uma forma mais abrangente e, partindo-se desses pressupostos, a concepção de cidadania competente organizada. Assim, entende-se que o número de projetos de pesquisa coletivos, na escola em tela, poderia ser proporcionalmente maior.

A questão 06 (do questionário E) investigou o processo de escolha do tema do projeto de pesquisa de cada estudante, obtendo-se as seguintes categorias de respostas: a partir de ideias dos próprios estudantes ( 5 respostas); por intermédio do professor orientador (5 respostas) e a partir de ideias dos colegas (2 respostas). Respostas à questão 07 (do questionário E) mostraram que 05 estudantes foram ter o seu primeiro contato com textos científicos no GIC, enquanto que as respostas à questão 09 (do questionário E) evidenciaram que 09 sujeitos (dos 11 participantes do GIC) tinham a intenção de continuar realizando pesquisas em sua vivência escolar. Esse conjunto de respostas tende a indicar não apenas a influência positiva dos docentes e das atividades de IC desenvolvidas na escola sobre os discentes envolvidos, como demonstra que a maior parte dos sujeitos passa a correlacionar a vivência escolar com a pesquisa, ideia defendida por Demo $(1992,2015)$.

A questão 10 (do questionário $\mathrm{E}$ ) indagava os discentes sobre os efeitos positivos das atividades desenvolvidas no GIC sobre o aprendizado de habilidades a serem aperfeiçoadas e desenvolvidas na escola. As respostas obtidas mostraram o seguinte: 05 estudantes afirmaram que obtiveram melhora na sua capacidade crítica; 04 estudantes informaram que o interesse nas aulas e nas matérias aumentou; 01 estudante afirmou que a realização de tarefas em casa melhorou; 01 estudante salientou que está mais dedicado na realização das atividades escolares. Sublinha-se que relatos semelhantes, sobre os efeitos da IC para o aprendizado discente, foram citados na literatura acadêmica (DAMINELLI, 2018; DAPPER; LEITE, 2016; GAUNA et al., 2018; MASSI; QUEIROZ, 2010).

\section{Investigando as respostas docentes}

A pergunta 02 (do questionário D) indagava sobre como o GIC influenciava o trabalho de cada docente. Segundo os professores, o GIC apresenta efeitos positivos, mas o destaque foi dado em relação aos resultados obtidos com os discentes (conforme excertos abaixo), evidenciando convergência com a literatura consultada neste artigo (CASTRO et al., 2018; DAPPER; LEITE, 2016; SILVA, 2018) e com as respostas informadas pelos estudantes (discutidas na seção anterior).

O GIC permite oferecer a oportunidade de um estudo diferenciado ao estudante, entre outras características, incentivando-o a buscar conhecimento. Nesse momento o estudante fica mais confiante e participativo nas aulas (resposta escrita no questionário, Professor P1).

Em termos linguísticos, contribuindo para o letramento científico dos estudantes. Em termos de pesquisa, motivando-os a experiências científicas que serão diferenciais em suas vidas acadêmicas (resposta escrita no questionário, Professor P2).

A pergunta 06 (do questionário D) interessava-se pela forma com que eram escolhidos os temas dos projetos. A resposta mais significativa foi dada pelo docente $\mathrm{P} 4$, na qual explicou que os estudantes que ingressavam no GIC, primeiramente participavam de todas as atividades (aulas, seminários e experimentos), ambientavam-se nos laboratórios, utilizavam equipamentos de medida e assistiam aos seminários dos professores e estudantes mais experientes. $\mathrm{O}$ docente $\mathrm{P} 4$ informou ainda que certos estudantes já chegavam com um assunto de pesquisa previamente escolhido (em caso de indefinição, eram sugeridas temáticas para a escolha do discente, de acordo com o perfil de cada sujeito); a partir disso, eram desenhadas possíveis estratégias para a realização de cada pesquisa (no tempo médio de 02 a 03 meses), sendo que os encontros do GIC eram realizados uma vez por semana, no turno oposto às aulas regulares. 
A pergunta 07 (do questionário D) indagava se os professores tiveram contato com pesquisa científica antes de entrar no GIC, o que foi confirmado por toda a amostra de sujeitos. Respostas à pergunta 09 (do questionário D) mostraram que os professores pretendiam continuar se dedicando à pesquisa, pois informaram que essa atividade era (excertos, a seguir, extraídos das respostas): "Muito importante para o meu crescimento profissional e dos meus alunos" (Professor P2); "A inclusão de iniciação científica no ensino básico é um projeto pessoal que estará continuamente se desenvolvendo" (Professor P3); “A pesquisa tem que fazer parte da sala de aula. Os estudantes têm que ser desafiados a curiosidade investigativa. O professor é um mediador" (Professor P4). Os dados sugerem a convergência do perfil docente (da amostra em tela) com o modelo de "Educar pela Pesquisa" (DEMO, 1992, 2015).

A pergunta 10 (do questionário D) investigava a visão docente sobre as habilidades escolares discentes que eram, possivelmente, aperfeiçoadas pela participação dos sujeitos no GIC. As respostas obtidas (apresentadas no Gráfico 3) relatam diferentes efeitos positivos, corroborando as respostas dadas pelos discentes. As respostas dos docentes também convergem com a literatura acadêmica, sobre os possíveis efeitos da IC sobre a aprendizagem (DAMINELLI, 2018; DAPPER; LEITE, 2016; SANTOS; PIZZATO, 2019; SOUZA et al., 2019; VARGAS; SOUSA, 2011).

\section{Gráfico 3 - Habilidades aperfeiçoadas pelos estudantes segundo os professores}

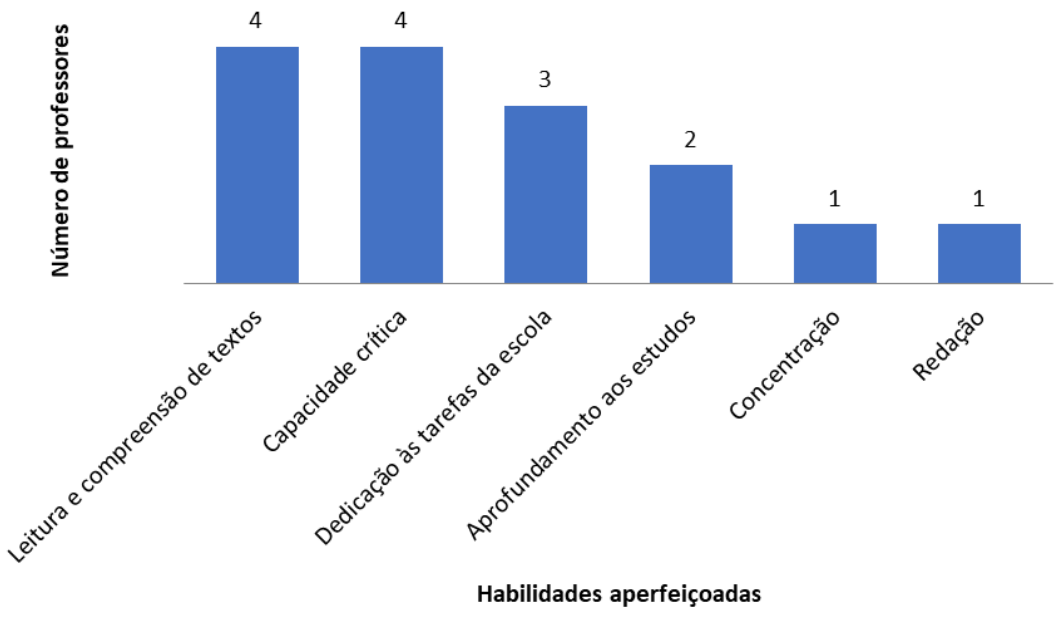

Fonte: Elaborado pelos autores com base nos dados obtidos

A pergunta 13 (do questionário D) era a seguinte: "Qual deve ser a relação do professor de educação básica com a pesquisa?”. Os docentes P1 e P2 salientaram que tal relação era essencial, visto que a pesquisa faz com que os professores estejam em constante atualização e aprendizado. O professor P3 cita a aproximação com os estudantes, o que também é citado por Massi e Queiroz (2010). Além disso, o professor P4 menciona que a pesquisa também proporciona estímulo para o professor/orientador, visto que permite organização e busca por novas formas de estudo, maior compromisso e responsabilidade, além de aumentar a resiliência. O papel do professor e sua relação com a pesquisa citados pelos docentes investigados (nas respostas mencionadas) converge com o entendimento de Demo (2015).

Por outro lado, não ficou evidenciado se as atividades de pesquisa estão isoladas no âmbito do GIC, ou se todo o conjunto de professores, na escola envolvida, é estimulado a organizar atividades investigativas, nas aulas regulares. Nesse ponto, destaca-se que seria importante que houvesse um movimento institucional mais amplo, no sentido de superação das limitações formativas características das aulas tradicionais (pensadas, sobretudo, como processo de instrução), ou seja, a mera reprodução da informação (cópia) e o paradigma do estudante ouvinte e domesticado (DEMO, 2015). 
Pelas informações obtidas e análises ora realizadas, o GIC parece funcionar como uma espécie de reduto institucional especial da escola em tela, reservado aos que apresentam o perfil/ interesse para pesquisa, tanto do ponto de vista dos estudantes, quanto no que concerne à integração docente às atividades investigativas e de orientação de projetos decorrentes destas. Esse contexto tende a caracterizar uma adesão institucional parcial ao ideário do "Educar pela Pesquisa" (DEMO, 1992, 2015): assume-se a escola como lócus do questionamento reconstrutivo da realidade e da emancipação do sujeito historicamente situado enquanto objetivo educacional, mas delimita-se a atividade de pesquisa a um grupo reduzido de sujeitos, àqueles que possuem maior inclinação à pesquisa (aqui, manifestada nas atividades de IC, na escola mencionada) e a um espaço específico da instituição escolar, não havendo comprometimento do tempo das aulas regulares para tais atividades e, possivelmente, avalizando-se que os processos mais transmissivos/expositivos tenham seu protagonismo garantido.

\section{Considerações Finais}

Os dados obtidos a partir deste trabalho reforçam a ideia de que a atividade de pesquisa tem um papel fundamental na educação básica, pois é também através desta que os estudantes adquirem uma postura investigativa em relação ao conhecimento (DEMO, 2015). Partindo-se do que foi apresentado e discutido neste artigo, torna-se possível a inferência de que houve uma convergência entre as concepções reveladas sobre os efeitos da IC, tanto de professores, quanto dos estudantes, após ingressarem no GIC e terem contato com a pesquisa, ressaltando-se que tal atividade de pesquisa (enquanto atividade pedagógica) trouxe melhorias para ambos. Nesse sentido, conclui-se que este trabalho atingiu os objetivos a que se propôs, considerando-se que os movimentos de pesquisa realizados conseguiram evidenciar a relação intrínseca da atividade de IC com o desempenho escolar dos estudantes, partindo-se da percepção dos sujeitos envolvidos (docentes e discentes).

Por outro lado, algumas limitações podem ser apontadas com relação aos resultados que foram obtidos nesta pesquisa, principalmente em relação aos questionários utilizados, que se mostraram insuficientes do ponto de vista de alguns aprofundamentos sobre os dados obtidos. Citam-se algumas lacunas que foram percebidas, após o encerramento da pesquisa, decorrentes dos questionários: I. ficaram dúvidas sobre as razões do envolvimento discreto de professores da área de Ciências Humanas da escola, com as atividades de IC no GIC; II. não houve informações sobre o regime de trabalho docente e sua remuneração, na escola citada, no que tange à participação docente nas atividades de IC, nem sobre como eram estabelecidos os critérios para ingresso docente como membro do GIC.

A segunda limitação, motivada pela pandemia de COVID-19 que assolou/assola o mundo nos anos de 2020 e 2021, foi a ocorrência de relativa dificuldade de diálogo com os gestores da escola citada, que se encontrava fechada durante os meses em que os dados desta pesquisa foram coletados, o que inviabilizou o acesso a documentos oficiais da escola, que poderiam ter sido fontes de dados sobre a visão político-pedagógica da instituição e sobre sua inserção na comunidade à qual atende. Infere-se que a realização de entrevistas poderia ter sido prevista, a fim de complementar os dados obtidos através dos questionários, o que certamente aponta para correções futuras, em projetos de pesquisa correlatos, a serem desenvolvidos pelos autores deste artigo. Observações das práticas de IC e dos espaços da escola em que estas eram realizadas, que poderiam enriquecer esta investigação, também foram impossibilitadas pela pandemia. Pondera-se, contudo, que essas limitações não invalidam os movimentos investigativos que foram realizados e as análises decorrentes destes que foram elaboradas e, neste artigo, apresentadas.

Este trabalho pode ser considerado gerador de reflexões sobre a escola, o trabalho do professor e o papel do estudante, bem como destaca tanto a importância da IC enquanto prática escolar, na educação básica, quanto a relevância desta como temática de pesquisa nos círculos acadêmicos 
educacionais do país. Assim, novas investigações com tal enfoque são requeridas e devem, convenientemente, aprofundar o tema, explorando, por exemplo, variantes políticas, sociais, culturais e econômicas, que são determinantes para a existência e o financiamento de programas de IC na educação básica, bem como para a delimitação de condições institucionais e profissionais de trabalho que permitam a ocorrência de tal atividade, e disseminar a ideia de que o espírito investigativo pode estar presente em diferentes ambientes escolares e interpelar/ser componente formativo de diferentes atores/protagonistas da educação básica brasileira.

\section{Referências}

ARAÚJO, Iata Anderson Ferreira de. Reino plantae: uma experiência contextualizadora de ensino de biologia na educação básica no município de Óbidos-PA. In: ENEBIO - I EREBIO NORTE, 7., 2018, Belém. Anais [...]. Belém: Universidade Federal do Pará, 2018. p. 1529-1535. Disponível em: https://sbenbio.org.br/wp-content/uploads/anais/ anais_vii_enebio_norte_completo_2018.pdf. Acesso em: 29 jan. 2021.

BARDIN, Laurence. Análise de conteúdo. 4. ed. Lisboa: Edição 70, 2010.

BRITO, Jhonata Rodrigues; FONSECA, Carlos Ventura. O tema da iniciação científica na educação básica a partir da produção acadêmica da área de Educação em Ciências da Natureza. In: ENCONTRO NACIONAL MOVIMENTOS DOCENTES, 1., [Diadema], 2020. Anais [...]. Diadema: V\&V editora, 2020, p. 157-163. Disponível em: https://doi. org/10.47247/VV/LAA/88471.03.6. Acesso em: 16 fev. 2021.

CASTRO, Cláudia Silva de Castro; SANTOS, Renata Repolho dos; ARAÚJO, Iata Anderson Ferreira de; PORTELA, Isa Helena Alves Loureiro; SILVA, Jardisson Luiz Rocha da. A iniciação científica por meio de projetos integradores: análise da avaliação dos estudantes. In: ENEBIO - I EREBIO NORTE, 7., 2018, Belém. Anais [...]. Belém: Universidade Federal do Pará, 2018.p. 5270-5280. Disponível em: https://sbenbio.org.br/wp-content/uploads/anais/anais_vii_enebio_ norte_completo_2018.pdf. Acesso em: 29 jan. 2021.

DAMINELLI, Elisa. A pesquisa e a produção de conhecimento nos institutos federais de educação, ciência e tecnologia no RS: um estudo sobre a iniciação científica com estudantes do ensino médio técnico. 2018. Tese (Doutorado em Educação) - Programa de Pós-Graduação em Educação, Universidade Federal do Rio Grande do Sul, Porto Alegre, 2018. Disponível em: https://lume.ufrgs.br/handle/10183/181860. Acesso em: 29 jan. 2021.

DAPPER, Jaqueline Mayer; LEITE, Fabiane de Andrade. Inter-relação universidade e escola básica por meio de programas de iniciação científica. Revista de Ensino de Biologia da SBEnBio, Niterói, v. 9, p. 1868-1880, 2016. Disponível em: https://rd.uffs.edu.br/bitstream/ prefix/2569/1/Dapper.pdf. Acesso em: 29 jan. 2021.

DEMO, Pedro. Educar pela Pesquisa. 10 ed. Campinas: Autores Associados, 2015.

DEMO, Pedro. Pesquisa: princípio científico e educativo. 12 ed. São Paulo: Cortez Editora, 1992.

GAUNA, Nádia Caroline Sobrinho; RODRIGUES, Luiz Felipe Faria; CARDOZO, Pedro Inácio Marcelino; MACHADO, Vera de Mattos. Ciências e filosofia em uma turma do ensino médio da escola José Maria Hugo Rodrigues. In: ENEBIO - I EREBIO NORTE, 7., 2018, Belém. Anais [...]. Belém: Universidade Federal do Pará, 2018. p. 4665-4671. Disponível em: https://sbenbio.org.br/wp-content/uploads/anais /anais_vii_enebio_norte_completo_2018.pdf. Acesso em: 29 jan. 2021.

GONZAGA, Graciele Batista; OLIVEIRA, Elaine Cecília Lima de. Práticas inovadoras caminhos para a iniciação científica na Educação Básica. Revista de Educação ANEC, Brasília, DF, v. 47, n. 160, p. 110-125, out./dez. 2019. Disponível em: http://revistas.anec.org.br/index.php/revistae ducacao/article/view/231. Acesso em: 16 fev. 2021.

LIMA, Isabel Van Der Ley; CARVALHO, Cristina. A iniciação científica em museus e centros de ciência: uma análise em instituições da Cidade do Rio de Janeiro (RJ). In: ENCONTRO NACIONAL DE PESQUISA EM EDUCAÇÃO EM CIÊNCIAS - ENPEC, 11., 2017, Florianópolis. Anais [...]. Florianópolis: UFSC, 2017. p. 1-7. Disponível em: http://www. gepemci.com.br/wp-content/uploads/2018/04/Lima-ENPEC-2017.pdf. Acesso em: 29 jan. 2021.

LONGHI, Adriana; SCHROEDER, Edson. Clubes de ciências: o que pensam os professores coordenadores sobre ciência, natureza da ciência e iniciação científica numa rede municipal de ensino. Revista Electrónica de Enseñanza de las Ciencias, Pontevedra, v. 11, n. 3, p. 547-564, 2012. Disponível em: http://reec.educacioneditora.net/volumenes/ volumen11/ REEC_11_3_4_ex650.pdf. Acesso em: 29 jan. 2021. 
LÜDKE, Menga; ANDRÉ, Marli Eliza Dalmazo Afonso de. Pesquisa em educação: abordagens qualitativas. São Paulo: EPU, 1986.

MASSI, Luciana; QUEIROZ, Salete Linhares. Estudos sobre iniciação científica no Brasil: Uma revisão. Cadernos de Pesquisa, São Paulo, v. 40, n. 139, p. 173-197, jan./abr. 2010. Disponível em: https://www.scielo.br/scielo.php?pid=S010015742010000100009\&script=sci_arttext\&tlng=p.Acesso em: 29 jan. 2021.

MAZON, Luciano; TREVIZAN, Auxiliadora. Fecundando o processo da interdisciplinaridade na iniciação científica. Revista Latino-Americana de Enfermagem, Ribeirão Preto, v. 9, n. 4, p. 83-87, jul. 2001. Disponível em: https://www. scielo.br/scielo.php?pid=S010411692001000400014\&script=sci_abstract\&tlng=es. Acesso em: 29 jan. 2021.

PERES, Ariadne da Costa; CAJUEIRO, Dayanne Dailla da Silva. A iniciação científica infanto-juvenil: ensinando ciência em um clube de ciências. In: ENEBIO - I EREBIO NORTE, 7., 2018, Belém. Anais [...]. Belém: Universidade Federal do Pará, 2018. p. 5217-5225. Disponível em: https://sbenbio.org.br/wp-content/uploads/anais/anais_vii_enebio_ norte_completo_2018.pdf. Acesso em: 29 jan. 2021.

PRESTES, Rosângela Ferreira; SILVA, Maria Marques da Silva. As contribuições do educar pela pesquisa no estudo das questões energéticas. Experiências em Ensino de Ciências, Cuiabá, v. 4, n. 2, p. 7-20, 2009. Disponível em: http:// www.if.ufrgs.br/eenci/artigos /Artigo_ID77/ v4_n2_a2009.pdf. Acesso em: 29 jan. 2021.

ROCHA, Lorraine dos Santos; SIMIÃO-FERREIRA, Juliana. Atividades investigativas no ensino de ciências: insetos aquáticos e a poluição dos rios. Experiências em Ensino de Ciências, Cuiabá, v. 15, n. 1, p. 242-257, 2020. Disponível em: https://if.ufmt.br/eenci/artigos /Artigo_ID689/v15_n1_a2020.pdf. Acesso em: Acesso em: 29 jan. 2021.

SAKAMOTO, Cleusa Kazue; SILVEIRA, Isabel Orestes. Como fazer projetos de iniciação científica. São Paulo: Cadernos de Comunicação, 2019.

SANTOS, Sandra Aparecida dos; PIZZATO, Michelle Câmara. Iniciação científica na educação básica: percepções de estudantes investigadores. In: ENCONTRO NACIONAL DE PESQUISA EM EDUCAÇÃO EM CIÊNCIAS - ENPEC, 12., 2019, Natal. Anais [...]. Natal: UFRN, 2019. p. 1-7. Disponível em: http://abrapecnet.org.br/enpec/xii-enpec/anais/ resumos/1/R0672-1.pdf. Acesso em: 29 jan. 2021.

SILVA, Maria Josiane da. A flora escolar como base de iniciação científica para estudantes do ensino médio. In: ENEBIO - I EREBIO NORTE, 7., 2018, Belém. Anais [...]. Belém: Universidade Federal do Pará, 2018. p. 264-271. Disponível em: https://sbenbio.org.br/wpcontent/uploads/anais/anais_vii_enebio_norte_completo_2018.pdf. Acesso em: 29 jan. 2021.

SOUSA, Isabela Cabral Félix de; BRAGA,Cristiane Nogueira; FRUTUOSO, Telma de Mello; FERREIRA, Cristina Araripe; VARGAS, Diego da Silva. Gênero e iniciação científica: a predominância feminina no programa de vocação científica na visão de seus alunos. In: PEREIRA, Isabel Brasil; RIBEIRO, Claudio Gomes (coord.). Estudos de Politecnia e Saúde. Rio de Janeiro: EPSJV, 2007. v. 2, p. 145-165. Disponível em: https://www.arca.fiocruz.br/handle/icict/39556. Acesso em: 29 jan. 2021.

SOUZA, Marta João Francisco Silva; OLIVEIRA, Gabrielle Teixeira de Oliveira; JESUS, Laura Beatriz Souza de; SANTOS, Marcelo Antônio Souza; MARTINS, Pablo Gonçalves. A iniciação científica no ensino médio na perspectiva dos orientadores: um estudo de caso no Instituto Federal de Goiás-Câmpus Jataí. In: ENCONTRO NACIONAL DE PESQUISA EM EDUCAÇÃO EM CIÊNCIAS - ENPEC, 12., 2019, Natal. Anais [...]. Natal: UFRN, 2019. p. 1-7. Disponível em: http://abrapecnet.org.br/enpec/xii-enpec/anais/resumos/1/R2204-1.pdf. Acesso em: 29 jan. 2021.

UNIVERSIDADE FEDERAL DO RIO GRANDE DO SUL (UFRGS). Salão de iniciação científica (SIC). Porto Alegre: UFRGS, 2020. Disponível em: http://www.ufrgs.br/propesq1/sic2019/. Acesso em: 3 jun. 2020.

VARGAS, Diego da Silva; SOUSA, Isabela Cabral Félix de. As práticas de letramento do programa de vocação científica da Fundação Oswaldo Cruz do Rio de Janeiro (PROVOC/Fiocruz): trabalho, ciência e formação identitária. Revista Electrónica de Enseñanza de las Ciencias, Pontevedra, v. 10, n. 1, p. 40-63, 2011. Disponível em: http://www.juventudect. fiocruz.br/sites/default/files/arquivos/vargassousa_letramento.pdf. Acesso em: 29 jan. 2021.

XAVIER, Patrícia Maria Azevedo; ALMEIDA, Maria José Pereira Monteiro de. A iniciação científica na educação básica: um olhar a partir dos anais do enpec. In: ENCONTRO NACIONAL DE PESQUISA EM EDUCAÇÃO EM CIÊNCIAS - ENPEC, 12., 2019, Natal. Anais [...]. Natal: UFRN, 2019. p. 1-7. Disponível em: http://abrapecnet.org.br/ enpec/xii-enpec/anais/resumos/1/R0654-1.pdf. Acesso em: 29 jan. 2021.

Data da submissão: 30/01/2021

Data de aceite: 16/02/2021 